\title{
Autism Employment Initiative in a Global Business Management Consultancy Firm: A Case Study
}

\author{
Rachel Friedfeld Kesselmayer ${ }^{1}$, ${ }^{\text {, Chase M. Ochrach }}{ }^{2}$ b, Brian N. Phillips ${ }^{3}{ }^{c}$, Ngonidzashe Mpofu ${ }^{1}$,, Beatrice Lee ${ }^{4}$ e \\ Xiangli Chen' ${ }^{1}$, David Geslak ${ }^{5}$, Timothy N. Tansey ${ }^{1}$ \\ 1 Rehabilitation Psychology and Special Education, University of Wisconsin-Madison, 2 Counseling Psychology, University of Wisconsin-Madison, 3 \\ Special Education and Rehabilitation Counseling, Utah State University, ${ }^{4}$ Department of Rehabilitation Sciences, The University of Texas at El Paso, 5 \\ Autism Workforce
}

Keywords: autism, disability diversity initiative, organizational change, employer practices

https://doi.org/10.52017/001c.32416

\section{Rehabilitation Counselors and Educators Journal}

Vol. 11, Issue 1, 2022

\begin{abstract}
Youth and adults with autism are being recognized for their ability to contribute to the labor market. This recognition has led to a growing number of employer-driven initiatives to recruit and hire from among this population. This descriptive case study presents a company-driven collaboration between a global consultancy management firm and a private human services provider to implement effective disability-related employer practices to hire and retain an employee with autism. Perceptions of implementation, effectiveness, and outcomes were collected. Results suggest that the changes made to accommodate a worker with autism were perceived positively by employees and had the potential to increase company performance. Company characteristics and proactive modifications to the workplace were identified as keys to success. Positive impacts on company performance, employee perceptions of the company, and overall perspectives regarding disability were reported across different levels of the company.

Recommendations for future implementation and replication are discussed. This case study implicates a potential model for companies to use when working to recruit and retain employees with autism. Rehabilitation counselors have an opportunity to help this growing number of motivated employers create effective initiatives that benefit both the company and the employee with autism.
\end{abstract}

Despite legislation such as the Americans with Disabilities Act (ADA) and Section 503 of the Rehabilitation Act, longstanding employment disparities persist among people with disabilities (Miethlich \& Oldenburg, 2019). People with disabilities are often left out of targeted diversity efforts and, as a result, overlooked in employer and human resource diversity statements, training, and practices (Byrd, 2009; Chan et al., 2010; Gould et al., 2019; Kendall \& Karns, 2019; Procknow \& Rocco, 2016; Ross-Gordon \& Brooks, 2004; Theodorakopoulos \& Budhwar, 2015). A report generated by the Return on Disability Group found that while $90 \%$ of surveyed companies prioritized diversity, only $4 \%$ included disability in their diversity initiatives (Casey, 2020; Donovan, 2020). People with autism spectrum disorder are among those experiencing the highest unemployment and the least consideration in company disability diversity efforts (Palumbo, 2021; Roux et al., 2015). Even when employed, adults with autism are disproportionately underemployed (e.g., Baldwin et al., 2014; Frank et al., 2018; Gerhardt \& Lainer, 2011) and underpaid (e.g., Lorenz \& Heinitz, 2014; Roux et al., 2013). It is unlikely that government initiatives alone will be sufficient to increase the employment of people with disabilities. To achieve full equity, employers will need to go from complying with laws to targeted hiring and retention efforts fueled by a belief that it will support overall company performance.

Recently, we have begun to see a shift among employers from disability inclusion, motivated by legal requirements and obligatory corporate social responsibility, to one driven by optimized company performance and effective work cli-

\footnotetext{
a kesselmayer@neurology.wisc.edu

b ochrach@wisc.edu

c brian.phillips@usu.edu

d nmpofu@wisc.edu

e ylee6@utep.edu

f xchen653@wisc.edu

g david@autismworkforce.com
} 
mates (Miethlich \& Šlahor, 2018). Instead of legal compliance, charity, or a public relations stunt, companies are more frequently citing efforts to gain a competitive advantage as primary reasons for recruiting job candidates with autism and other disabilities (Accenture, 2018; Donovan, 2020; Miethlich \& Šlahor, 2018; Shattuck, 2019). In this changing landscape, companies are increasingly creating their own initiatives to hire and retain employees with autism (e.g., Frank et al., 2018; Hedley et al., 2017; Howlin, 2013; Huang \& Chen, 2015; Hurley-Hanson et al., 2020; Lindsay et al., 2018; Wharton Business Daily, 2019). These initiatives, although growing, are still poorly understood and have yet to reduce unemployment significantly among adults with autism (Bernick, 2021; Granat, 2020; Griffiths et al., 2020; Nicholas \& Klag, 2020).

Most research attention has been given to large-scale efforts that employ dozens of people with autism. However, effectively reducing disparities will likely require several small-scale efforts in addition to the widely celebrated, but relatively small, number of large-scale efforts. A major gap in the literature exists in understanding best practices for employers who recognize neurodiverse applicants and employees as a key aspect of their overall business strategy but do not know where to start (Miethlich \& Oldenburg, 2019). In this case study, we describe the efforts of a global consultancy firm to collaborate with a private human services organization to create a position for an employee with autism who required multiple social and environmental modifications to accomplish the work being performed. Identifying employer practices implemented by businesses with a successful record of hiring people with autism can help rehabilitation counselors and employers see inclusion and integration of disability as a business opportunity employers can initiate now in small but meaningful ways (Casey, 2020).

\section{Methods}

The purpose of this descriptive case study was to analyze the company-driven partnership between a global consulting firm (Oliver Wyman) and a private human service organization (Autism Workforce), aimed at recruiting, hiring, and training an individual with autism. The magnitude of the study's importance is not adequately captured by the number of people with autism employed through the collaboration. As previously noted, we believe that reducing the longstanding employment disparity for people with autism will most likely be accomplished through the small efforts of several employers even more than the large efforts of a few. The utility of a case study to investigate experiences in a real-life context allows researchers to capture the perspectives of multiple sources about the implementation and reception of just such an intervention (Baxter \& Jack, 2008; Crowe et al., 2011; Yin, 2018).

\section{Procedures}

The research team consisted of faculty and doctoral students across two universities in the United States. Data collection efforts were carried out over the course of a year and comprised a thorough review of company policies, procedures, and written materials; review of the company website; an on-site visit; and individual and group interviews.
Before the site visit, researchers requested Oliver Wyman to relay documentation of the following: recruitment, retention, and promotion policies; company mission and vision statements; diversity statement; and any other written communications relevant to the creation of a disability-inclusive company culture or disability initiative. These written items, in addition to the company website, were reviewed by research team members to learn more about the company's disability efforts and were referenced to complete a 70-item disability climate and policy checklist that was developed as part of a broader project. Items from this checklist include a consideration of whether the company has strategies to attract qualified applicant with disabilities, whether they participate in job fairs for people with disabilities, whether they offer an employee assistance program, and whether they identify disability as a topic in diversity inclusion. Each item is answered with a yes or no response. When answering in the affirmative, the person completing the checklist will state the location where supporting materials can be found (e.g., employee handbook or website). A member of the research team completed this measure by indicating whether or not each item was present in the company. Two additional team members also independently reviewed the checklist and met to discuss disagreements and obtain consensus.

One on-site visit was completed at an Oliver Wyman location in the United States. Leadership from Oliver Wyman and Autism Workforce were asked to invite participation in individual interviews for employees who were highly involved in creating or executing day-to-day operations of the disability initiative. Additionally, leadership was asked to invite participation from employees who had some familiarity or experience with the disability initiative into two focus groups. The analysis team met before the site visit to discuss previously obtained information, outline expectations, and plan for addressing potential biases to promote data quality. This meeting was recorded to allow for later reference. During the site tour, Oliver Wyman staff were asked to highlight accommodations or adjustments made to the physical space to provide a disability-inclusive environment, efforts towards universal design, and any noted barriers or facilitators to disability inclusivity in the physical space. Five 30-minute individual interviews and two 45-minute focus groups were completed during the visit with consultant staff, supervisors, and management/executives. Written informed consent was obtained from all individual participants included in the study prior to initiating the interviews or focus groups. The individual interviews were conducted with three members of the leadership team and two consultants directly involved in the disability initiative. Two focus groups were then conducted with additional employees, with one group of four who had received the Autism 101 training from Autism Workforce and another group of three who had not. The absence of the leadership team from focus groups was designed to encourage more candid responses.

All interviews and focus groups followed semi-structured interview protocols comprised of open-ended questions designed to elicit understanding about all salient facets of Oliver Wyman's experiencing in hiring a person with autism. This provided consistency across interviews, but 
also permitted interviewers to pursue questioning related to the unique perspectives of each individual or group member. The analysis team met immediately after the interviews to debrief. This debriefing was also recorded for later use in analysis and reporting. Audio recordings of all completed interviews and meetings were placed on a secure internet-based server for transcription provided by a paid transcription service. Informed consent was obtained from all individual participants included in the study. Approval from the university's Institutional Review Board was also obtained to conduct this study with human subjects.

\section{Organizations}

Oliver Wyman is a global business management consultancy firm specializing in services to assist companies across industries improve their performance by providing expertise in operations, strategy, organization, and risk management. An impact statement indicates "Oliver Wyman people carve out their own areas of expertise within our diverse, non-hierarchical partnership. They are free to challenge conventional thinking, identifying new opportunities, and develop unique solutions for our clients." With its headquarters in New York City, Oliver Wyman employs over 5,000 professionals in 60 cities across 29 countries.

Autism Workforce, a for-profit, social-driven company pioneering workplace modifications and training to support employees with autism, educates and trains companies around recruiting, hiring, and training employees with autism through the implementation of a research-based employment model. To ensure successful collaboration, this model includes customized consideration of employee interests and company needs while also preparing both the company and the candidate with autism. Autism Workforce utilizes a three-step approach: (1) staff training and enlightenment, (2) workplace and job preparation, and (3) employee onboarding. Their mission statement reads, "We are driven to help companies enjoy the benefits of employing this ready, willing, and able workforce. Using well-thoughtout and proven strategies, we bridge the gap between good intentions and the need to take care of business." Oliver Wyman is among a diverse group of companies across business sectors that have partnered with Autism Workforce. Others include Prater, G\&W Electric, Hart Schaffner Marx, and IMEC.

\section{Data Analysis}

Data analysis and coding were performed initially by the lead author using both the transcribed interviews and original audio recordings using qualitative content analysis in a case study framework (Cho \& Lee, 2014; Merriam \& Tisdell, 2016; Yin, 2018). Audio files and transcripts were first reviewed to identify responses to primary questions asked by the interview team. From there, early themes were identified and these, along with the corresponding statements from the written information, interviews, and focus groups, were accrued into an Excel document. This process involved identifying objective efforts (i.e., policies and statements about employer policies and practices) in addition to subjective information about how those efforts affected the people and outcomes of the collaboration between Oliver
Wyman and Autism Workforce. This was an iterative process that involved creating themes and subcategories/ domains of the coded information and subsequent communication. A second coder also reviewed all transcripts and written documents before reviewing these themes and domains to ensure the accuracy of the analysis and ultimately corroborate the findings. Once data analysis was complete, the manuscript was sent to Oliver Wyman to ensure the information drawn from interviews and written materials was clear and accurate.

\section{Results}

The autism initiative at Oliver Wyman, a business management consultancy, was undertaken in partnership with Autism Workforce to hire individuals with autism. A qualitative case study approach was used to gain a pragmatic, in-depth, and multifaceted understanding of the employment of people with autism through this partnership. The employee with autism was Caucasian, held a bachelor's degree in computer science, and was in his late twenties at the time of the interviews. He was initially hired at eight hours a week, with the potential to increase those hours based on the interest and need of the employee and employer. The employee with autism was tasked with various responsibilities that did not involve direct client contact. These included computer coding, update and quality control of procedural and administrative files, and data entry. These tasks were selected based on company need, as well as on the skills and interests of the employee with autism. Individual and small group semi-structured interviews were conducted with staff and administrators. The present study explores the perspectives of the autism employment initiative and characteristics of the business which were attributed to its success.

The research team sought to gain a deep understanding of the employment of people with autism through the identification of key aspects of the collaboration between Oliver Wyman and Autism Workforce. Systematic review and analysis of group and individual interviews, on-site observations, written policies (e.g., Autism Workforce guide, employee handbook), and the climate survey resulted in the three primary categories: (a) Company Characteristics, (b) Influence of the Initiative, and (c) Evaluations and Recommendations. The following is a review of these categories and their domains.

\section{Company Characteristics}

A thorough review of interviews and written materials procured from Oliver Wyman indicated that pre-existing company characteristics, specifically a culture of social activism and social consciousness, as well as an employeecentered atmosphere, facilitated the implementation and reception of the autism initiative.

\section{Social Activism and Social Consciousness}

Echoed across all levels of team members at Oliver Wyman was a deeply ingrained company culture of social activism and social consciousness. Per an office leader, the "fabric of culture here [at Oliver Wyman]" is inclined toward 
helping. The workforce comprised of actuarial consultants and analysts was described by a member of the human resources team as having "social activism in their DNA" and by a practice lead as being "very concerned about social responsibility and giving back.” These perspectives were affirmed by one of the consultants who noted "...the upcoming generation likes to see those things [companies giving back to communities]". Company efforts to create such a culture were not going unnoticed, as a relatively new analyst to Oliver Wyman asserted, "A general sense that I get from the company is that they are very open to giving back to the community". Written documentation and the company website corroborated interviewees' comments about Oliver Wyman's focus on civic engagement. Of note is MisSionINCLUDE, an inclusion and diversity program that provides initiatives and opportunities to people with diverse characteristics (e.g., disability) and the Non-Profit Fellowship, a program available to employees which, according to the policies and written practices, "allows staff to work for a non-profit organization for 3-6 months" at $40 \%$ of their usual salaries.

Multiple people noted Oliver Wyman's culture of social activism and social consciousness as key values that were reinforced among recruits and employees. One employee, reflecting on these strongly held values stated that Oliver Wyman was "not your typical corporate environment." A member of the human resources team further explained that Oliver Wyman was unique from most other companies in that employees had a "very, very high social radar." Finally, an actuarial consultant attested to the broad range of opportunities and affirmed "I like being able to have that [company support for civic engagement opportunities]. It's something that's important to me, so I like being able to have that supported by the place I work for.”

\section{Employee Centered}

From interviews, it was made clear that intricately tied to Oliver Wyman's culture of corporate altruism is their emphasis on being an employee-centered company. Interviewees consistently spoke of Oliver Wyman's willingness to address the social and environmental needs of employees as they arose. Reflecting on the experience of a fellow employee who needed time to recover from an injury, an actuarial consultant stated that "management will definitely work with us to get things done, because, at the end of the day, we're valuable to the company." Another consultant shared a direct experience with Oliver Wyman's employeecentered approach at a time of need in stating:

There's a lot of flexibility to work from home. That's probably the biggest support, or flexibility, that I would say is currently built into the Oliver Wyman culture. My son has cerebral palsy, and there's a lot of flexibility with work to take him to the appointments even independent of using your sick time. He had surgery last year that required me to work really weird hours and that was totally accepted. I didn't have to take much time off from his surgery because I was able to work at home and also care for him the way that I needed to.

The prominent message of employee centeredness and flexibility apparent across several consultants was noted by a head of human resources as part of the "different world" that constitutes Oliver Wyman. In speaking of Oliver Wyman employees, a member of human resources team stated that leadership's inclination is to "just support people's lives” when possible. These pre-existing characteristics of Oliver Wyman and the culture of investing in the community and social initiatives appeared to help facilitate the collaboration with Autism Workforce, aimed at building a more inclusive workplace for the hiring of an employee with autism.

\section{Influence of the Initiative}

Management at Oliver Wyman acknowledged that disability has not always been a leading emphasis for diversity in their company, but that this emphasis had increased in recent years. A member of the human resources team explained that the "firm tends to gravitate towards educational initiatives and microfinance initiatives.” We proceed with a consideration of how interviewees described the influence of the autism initiative across several key facets of Oliver Wyman including company performance, company climate, and perceptions of disability.

\section{Company Performance}

Multiple employees stated that the employee with autism improved company performance by reliably completing work that was useful but often not prioritized. Across consultants there appeared to be a consensus that the work delegated to the hired employee with autism allowed them to focus on more immediate and pressing tasks. For example, one consultant said the following about the employee with autism:

He does work that had previously been the tasks of people who didn't have time for it as it was not the main portion of their job. We worked together to come up with a process that would allow [the employee with autism] to do it, and that cut [the principal leader's] time from like three hours to maybe 15 to 30 minutes a month on this task. The [employee with autism] does the heavy lifting on this task and [the principal leader] is able to spend his time on things that he should be spending his time on.

By identifying tasks that were essential but not the essential functions of consultants, Oliver Wyman employees stated that the autism initiative was "definitely helping [them] be more efficient in [their] work.” Consultants also realized tasks assigned to the employee with autism, which were previously thought to be unimportant, were quite valuable. As one consultant stated,
He's helping us make PowerPoints and keeping track of certain data that we do on a day-to-day basis. Since the end of the year, he's been doing it every single month. So now we have a big database that we can use and pull in- formation from. We wouldn't have a major loss without [this database], but it's information that definitely adds value and leads to efficient insights [for our customers].

Another consultant supported this perspective saying, "the work that he's doing behind the scenes definitely helps the team and the performance as a company." 


\section{Company Climate and Perceptions}

Beyond company performance, several spoke to the autism initiative's influence on company climate at Oliver Wyman, as well as on its influence of perceptions of the company as a whole. Multiple consultants indicated positive reactions to the autism initiative similar to the following:

\section{I had never heard of anything like this. Then, when I heard that Oliver Wyman is doing it, I thought it was great that we were open and willing to try it out, and it's worked out really well. It definitely gave a more positive impression of the company.}

Sharing similar sentiments, another consultant stated, “I am glad to be at a company that would be willing to put in the time and effort to do this. It's not a small thing." While it was clear the autism initiative promoted a positive image of the company among consultants and company leadership, perceptions of how the initiative influenced company climate and culture were more varied. Interestingly, those who saw little change in the company culture attributed it to the employee with autism integrating smoothly into the environment at Oliver Wyman. For instance, one consultant shared that he did not feel like the climate in the office had changed because "[the employee with autism] was doing his own work in a way that was on par with the status quo of the pre-existing office environment.”

\section{Perceptions of Disability}

Reflecting on the initiative, a practice lead stated that the process had been "an eye-opener on what people with disabilities struggle with that you might not even assume." This was reiterated by a global team member who explained, "working with [Autism Workforce] educated me on the complexity that employment represents for somebody with a disability." Despite the intricacies involved in the employment process for individuals with autism, an office lead stated that the initiative "just reinforced that concept that disabilities aren't a permanent situation that can't be dealt with." This comment is a testament to how the initiative shifted perceptions and preconceived notions of disability and employing people with autism. From the interviews, there appeared to be a generally shared belief that expectations for the employee with autism should be tempered, not out of malice, but rather an uncertainty about abilities. When discussing initial presumptions versus the employee with autism's actual performance, a practice leader stated,

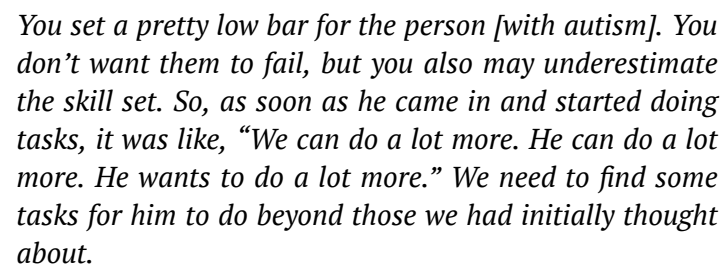

Another office lead also spoke to how the employee with autism surpassed initial expectations in saying, "He completes the task much faster than what we were ever imag- ining, and his skill set is much broader and more expansive than what we even realized when we hired him.”

\section{Evaluations and Recommendations}

Several elements were identified in the research as being critical to the longevity of the autism initiative at Oliver Wyman, and its potential replication in other companies. First, Oliver Wyman employees spoke to the importance of motivation. Speaking to this point, a practice leader stated, "The first thing to appreciate is that it's not charity. It's a positive impact to your company. There are tasks in your company that people with disabilities can do that will make a positive impact to the bottom line." A consultant at Oliver Wyman echoed this sentiment in saying, "a company shouldn't be doing [an autism initiative] for charity." He went on to state that Oliver Wyman was motivated towards such an initiative for the "value we get out of it." Several individuals, including an office lead, suggested that identifying a return on investment would be important in considering both current and future initiatives. He stated, "It can't be a charity case that doesn't create value. It doesn't necessarily have to generate the highest return on investment, but it does need to generate some return.” Although return on investment can be hard to accurately quantify with personnel, two consultants separately suggested shared their observation that return on investment was not yet clear. Said one consultant,

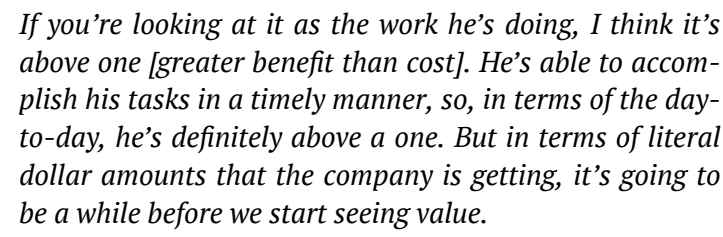

If you're looking at it as the work he's doing, I think it's above one [greater benefit than cost]. He's able to accomplish his tasks in a timely manner, so, in terms of the dayto-day, he's definitely above a one. But in terms of literal dollar amounts that the company is getting, it's going to be a while before we start seeing value.

A practice leader stated, after a more thorough analysis of return on investment taking into account employee compensation versus employee contribution, "It all works, and if we hire another, it works even better." When asked to clarify whether a positive return on investment had already been achieved, this leader stated, “Not yet, because he's not working as much as we would like him to, and that's our fault. It's not his fault." These comments provided additional understanding about the process involved in creating such an initiative, while also confirming the real potential for long-term benefits from such an effort.

Consistent with the employee-centered nature of Oliver Wyman, leadership and management support were also key factors in the success of the initiative. This sentiment was expressed across all levels. One consultant stated,

\footnotetext{
A big part of the success was that leadership was on board. We have support from very senior leadership that this is a valuable thing for us to spend our time on. Knowing that this is an investment and them being on board with the investment made it way easier and continues to make it way easier.
}

These observations were also apparent at the partner leader level. Said one leader, "You've got to be passionate about it. You have to have someone leading the charge. 
Otherwise, it would take a lot of effort from an HR standpoint to get that moving."

Areas for improvement primarily focused on open communication about the program and process, as well as recruiting more help from existing staff to integrate and support the employee with autism. One consultant who worked closely with the employee shared that, with hindsight, the initiative may have had a smoother start if more employees had been informed about what was happening and were encouraged to get involved before the initiative. Several individuals also emphasized the commitment of time necessary to support the initiative and the hired individual to be successful. Questions arose about whether the employee with autism could continue to be engaged at the same level if the primary junior associates working with him were unable to dedicate time to supporting his work. To address this concern, one consultant suggested engaging more individuals to recognize the value of the initiative:

You know, a partial solution is a greater awareness within the company, or just within this office, on what he's capable of doing. We've had conversations like that before just to make sure that people feel engaged with this process.

Final reflections about the future of the program pointed back to the idea that the initiative is still a work in progress. As one executive stated, "If we just have the individual doing the same task a year from now that he's currently doing, that's a problem." This leader added,

I don't think [the employee doing only a limited number of tasks] will be a problem that we're going to encounter in the very near future because the list of possibilities that are on the table is very long. It's more, "How are we going to get this person staffed up and trained up enough so they can do these tasks, and how are we going to find the resources to support that?"

As a means to combat any potential future issues with stagnation, positive reinforcement was suggested as an anecdote of sorts to reengage the staff, "You know, shining a spotlight on the good that they're doing periodically will reenergize and refuel the effort."

\section{Discussion}

Despite the benefits of hiring employees with autism becoming increasingly apparent to employers (Johnson et al., 2020), employment options remain limited-perpetuating high rates of unemployment and underemployment that are expected to be exacerbated in the post-COVID-19 job economy (Bush \& Tassé, 2017; Dreaver et al., 2020; Frank et al., 2018; Johnson et al., 2020; Maraoto \& Pettinicchio, 2020; National Organization on Disability, 2020). Calls have been made for research to investigate avenues to improve employment outcomes, with particular attention to employment access, career development, and employment retention among people with autism (Brooke et al., 2018; Johnson et al., 2020; Nicholas et al., 2019; Wehman et al., 2017; Wei et al., 2018). This case study explored the perspectives of consultants and senior management at Oliver Wyman. Responses to the incorporation of the employee with autism in this global consulting firm provide important understanding about initiating a successful effort to hire and retain people with autism.

Three main contributions to this research effort emerged from this case study. We identified several pre-existing characteristics deemed to be essential in facilitating the implementation of the autism initiative. High levels of social activism and social consciousness, in combination with being an employee-centered company, were described by the interviewees as key to the successful integration of an employee with autism, requiring modifications and added support to be successful in the workplace. Company characteristics, such as socially minded values and an employee-centered culture, can play an important role in workplace inclusion and creating an environment in which individuals with disabilities thrive (Gilbride et al., 2003, 2006; Stone \& Colella, 1996). This focus on company climate and values is supported by elements of the Interactional Model of Cultural Diversity (IMCD; Cox, 1993). According to the IMCD, organizational factors, including organizational culture, serve to predict overall success in creating a diverse company culture. Our research supports and refines this hypothesis by providing a description of specific company characteristics that produce a supportive company culture. Rehabilitation counselors and other human service providers looking to collaborate with employers in employer-led initiatives may benefit from screening for these company characteristics to increase the probability of success.

Second, participation in the autism initiative and the employment of an individual with autism improved efficiency, while also improving attitudes about disability. Similar findings were observed in a report of employers who participated in a job readiness initiative with individuals with autism (Nicholas et al., 2019). Similar to the findings at Oliver Wyman, employers who participated in the program reported several direct benefits, including increased productivity across all employees and greater understanding of people with autism (Nicholas et al., 2019). One implication for rehabilitation counselors to share with employers who express interest in a disability initiative but are concerned about how employees will respond is that, based on the literature and this case study, employees without disabilities tend to convey more positive perceptions of disability and greater appreciation for the company as they move forward with such efforts. Further, workplace diversity and inclusion have been identified as key to improving community relationships, job retention, and creativity (Unger, 2002). This is consistent with research that suggested an inclusive, supportive, and diverse workplace plays an important role in the work performance, productivity, and job success of employees with disabilities and their co-workers (Wehman, 2003).

Lastly, while it is anticipated the autism initiative will continue at Oliver Wyman, several factors have been cited in the literature that may contribute to the program's longevity and replication. Prior human resource development literature suggested direct CEO and leadership support not only legitimize efforts and initiatives of human resource departments, but also serve as a model for other employees (Trullen et al., 2016). In addition to leadership support, retention requires flexibility from existing employ- 
ees who supervise, interact, or collaborate with the employee with autism (Mawhood \& Howlin, 1999). Previous case study research suggested that these types of interactions are greatly facilitated through training employees on the potential differences and opportunities in communicating and working with an employee with autism (Grenawalt et al., 2020). In addition, employees with autism may need extended support to maintain workplace performance, as unexpected changes could be disruptive (Hendricks, 2010). Autism Workforce has played a key role in directly providing or consulting in regards to this support. Keen attention to this information is imperative, as interviews from the present study indicate more support and early involvement from co-workers is to likely assist in the integration of employees with autism in the workplace, a recommendation specific for future implementation. That said, rehabilitation counselors may be able to play a critical role in facilitating these natural supports and repairing them if needed.

Considering the results together, rehabilitation counselors must recognize two main points: (a) more and more companies are recognizing the opportunity in targeting the employment of people with disabilities, and (b) sufficient planning, time, effort, and resources are needed to ensure that disability employment initiatives provide the competitive advantage and company benefits described. A token hire of a person with disability is not likely to generate the positive outcomes that are available to companies who are sincere in their motive and committed to its success. Rehabilitation counselors can help employers to appreciate that this is no different than for any other hire, even if disability may present with some unique considerations in some circumstances.

Rehabilitation counselors seeking greater involvement or success in collaborations with employers may benefit from the insights generated from this case study in multiple ways. First, although employer-led disability initiatives are becoming more common, not all employers are interested in or positioned to take on such efforts. In line with the work of Gilbride et al. (2003), who provided a means for assessing employer openness to hiring people with disabilities, we have described more general company conditions, characteristics, and values that support such an effort. As rehabilitation counselors come to know the businesses in their area, they would do well to recognize the level of these qualities in each one. Our research would suggest that even an employer who can be convinced to hire a person with disabilities may not provide a company climate that is conducive to employees' long-term success.

For companies with an adequate climate, rehabilitation counselors must position disability employment efforts as a business opportunity, and potentially a competitive advantage, rather than falling back on notions of charity. Sometimes this requires helping employers to appreciate the various ways employees with disabilities can improve company performance. In the case of Oliver Wyman, this was largely through recognition of critical job functions that were taking time away from the essential functions of current employees and assigning these to a competent worker with disabilities who can efficiently and effectively complete the tasks. Other benefits to a more diverse workforce can come from the introspection they cause. For example, mention was made that greater efforts to document procedures and training components generally has had a more universal benefit for company procedures and training. Finally, as was the case at Oliver Wyman, employees are increasingly seeking to make an impact that goes beyond a singular company objective or profits. This and other case studies (e.g., Grenawalt et al., 2020) suggest that disability employment initiatives can improve company climate by giving added meaning and mission to a company in the eyes of employees. All new hires, disability or not, present with some risk they will not work out. That said, rehabilitation counselors who recognize the potential opportunities for companies that include people with disabilities can confidently share the business case for focusing on this historically neglected candidate pool.

\section{Study Limitations and Research Recommendations}

The results from this case study should be considered within the context of a few limitations. First, while providing valuable insight and content to the experience of an autism initiative at Oliver Wyman, this is the experience of one company in the global management consultancy arena. As such, caution should be exercised when generalizing the results to other companies. Looking forward, it would be interesting to evaluate a similar collaboration across businesses in other sectors and industries. Inherent to focus groups, it is possible that comments from one participant influenced those of others. Several researchers reviewed the content of the interviews and written materials to discern themes based on patterns identified in the data. Though this contributed to a process to analyze the data objectively and served as an informal audit, it is suitable to suggest that another research team may have drawn different conclusions and interpretations of the data. In the face of these limitations, it is believed the present study provides important implications for the implementation of an autism initiative by reviewing the perspectives of employees and leadership to understand inclusive employment practices. Multiple studies have examined initiatives and programs targeted toward individuals with autism with an aptitude for coding or other technology related jobs (Baldwin et al., 2014; Caron et al., 2004; Cullum \& Ennis-Cole, 2014; Krzeminska \& Hawse, 2020; Mawhood \& Howlin, 1999). More research is still needed to identify best practices for recruiting and retaining individuals with autism who have varying abilities and interests.

In any company-led effort to employ one or a small proportion of people from a specific group or population, there is a potential risk for tokenism (Cox, 1993). There is also the potential for employers to limit opportunities within the company based on a single characteristic (i.e., role entrapment; Abou-Dahech \& Gabel, 2020). This case study corroborates with the limited literature base suggesting a company culture that values diversity, inclusion, and equity can increase the likelihood that company-driven efforts to employ people with disabilities will have positive effects for the company and the people with disabilities whom they hire (Hutton et al., 2010). Company perceptions of their disability initiative suggested a valuing of diversity and an ap- 
preciation for performance gains in the company from the targeted hiring of an employee with autism. Nevertheless, more accurate assessment of perceived tokenism could be gained by including the perceptions of the employee with disabilities in future research.

\section{Conclusion}

Case study results indicate a positive response to the autism initiative at Oliver Wyman. The long-term stability and growth of this initiative will ultimately rest on the capacity of Oliver Wyman to identify the business case for the program. Universal organizational initiatives and accommodations, similar to those described at Oliver Wyman, have previously been found to not only promote the career development of people with disabilities but also encourage feelings of equality across all employees (Kulkarni, 2016).
More work is needed to understand how research and practice initiatives can together inform the symbiotic benefits of expanding employer recruitment pools, improving accessibility for applicants of different abilities, and supporting and accommodating employees with autism. The integration and reintegration of people with disabilities and autism into the workforce in a post-COVID-19 economy will depend on several factors, including the return of autism employment initiatives and efforts operating at pre-pandemic levels (Bernick, 2021; Brooks, 2020). Identifying the characteristics and practices of companies that have successfully developed disability initiatives can serve as a roadmap for businesses, vocational rehabilitation agencies, and stakeholders who will need to work even harder to ensure success for employees with disabilities moving forward (Chan et al., 2021). 


\section{References}

Abou-Dahech, T., \& Gabel, R. (2020). Vocational stereotyping of people who stutter: Human resource management students. Perspectives of the ASHA Special Interest Groups, 5(5), 1139-1146. https://doi.o rg/10.1044/2020 persp-20-00003

Accenture. (2018). Getting to equal: The disability inclusion advantage. The American Association of People with Disabilities (AAPD) and Disability: IN. htt ps://www.accenture.com/_acnmedia/pdf-89/accentur e-disability-inclusion-research-report.pdf

Baldwin, S., Costley, D., \& Warren, A. (2014). Employment activities and experiences of adults with high-functioning autism and Asperger's disorder. Journal of Autism and Developmental Disorders, 44(10), 2440-2449. https://doi.org/10.1007/s10803-014-211 $\underline{2-z}$

Baxter, P., \& Jack, S. (2008). Qualitative case study methodology: Study design and implementation for novice researchers. The Qualitative Report, 13(4), 544-559.

Bernick, M. (2021, January 12). The state of autism employment in 2021. Forbes. https://www.forbes.co $\mathrm{m} /$ sites/michaelbernick/2021/01/12/the-state-of-auti sm-employment-in-2021/?sh=2632cd0c59a4

Brooke, V., Brooke, A. M., Schall, C., McDonough, J., Thompson, K., \& Smith, J. (2018). Employees with autism spectrum disorder achieving long-term employment success: A retrospective review of employment retention and intervention. Research and Practice for People with Severe Disabilities, 43(3), 181-193. https://doi.org/10.1177/1540796918783202

Brooks, J. D. (2020). Workers with disabilities may remain unemployed long after the COVID-19 pandemic [Issue Brief \# 30]. Syracuse University Lerner Center for Public Health Promotion.

Bush, K. L., \& Tassé, M. J. (2017). Employment and choice-making for adults with intellectual disability, autism, and down syndrome. Research in Developmental Disabilities, 65, 23-34. https://doi.org/ 10.1016/j.ridd.2017.04.004

Byrd, M. Y. (2009). Diversity training: What are we really talking about. In T. J. Chermack, J. Storberg-Walker, \& C. M. Graham (Eds.), Academy of Human Resource Development conference proceedings (pp. 203-208). Academy of Human Resource Development.

Caron, M. J., Mottron, L., Rainville, C., \& Chouinard, S. (2004). Do high functioning people with autism present superior spatial abilities? Neuropsychologia, 42(4), 467-481. https://doi.org/10.1016/j.neuropsych ologia.2003.08.015

Casey, C. (2020, March 19). Do your D\&I efforts include people with disabilities? Harvard Business Review. htt ps://hbr.org/2020/03/do-your-di-efforts-include-peop le-with-disabilities
Chan, F., Strauser, D., Maher, P., Lee, E.-J., Jones, R., \& Johnson, E. T. (2010). Demand-side factors related to employment of people with disabilities: A survey of employers in the Midwest region of the United States. Journal of Occupational Rehabilitation, 20(4), 412-419. https://doi.org/10.1007/s10926-010-9252-6

Chan, F., Tansey, T. N., Iwanaga, K., Bezyak, J., Wehman, P., Phillips, B. N., Strauser, D. R., \& Anderson, C. (2021). Company characteristics, disability inclusion practices, and employment of people with disabilities in the post COVID-19 job economy: A cross sectional survey study. Journal of Occupational Rehabilitation, 31(3), 463-473. https://d oi.org/10.1007/s10926-020-09941-8

Cho, J. Y., \& Lee, E.-H. (2014). Reducing confusion about grounded theory and qualitative content analysis: Similarities and differences. The Qualitative Report, 19(32), 1-20. https://doi.org/10.46743/2160-3 715/2014.1028

Cox, T. H. (1993). Cultural diversity in organizations: Theory, research \& practice. Berrett-Koehler.

Crowe, S., Cresswell, K., Robertson, A., Huby, G., Avery, A., \& Sheikh, A. (2011). The case study approach. BMC Medical Research Methodology, 11(100), 1-9. http s://doi.org/10.1186/1471-2288-11-100

Cullum, P. M., \& Ennis-Cole, D. (2014). Preparing adults with autism spectrum disorders for employment. Online Journal for Workforce Education and Development, 7(1), 6.

Donovan, R. (2020). Design delight from disability. Report summary: The global economics of disability. Return on Disability.

Dreaver, J., Thompson, C., Girdler, S., Adolfsson, M., Black, M. H., \& Falkmer, M. (2020). Success factors enabling employment for adults on the autism spectrum from employers' perspective. Journal of Autism and Developmental Disorders, 50(5), 1657-1667. https://doi.org/10.1007/s10803-019-0392 $\underline{3-3}$

Frank, F., Jablotschkin, M., Arthen, T., Riedel, A., Fangmeier, T., Hölzel, L. P., \& van Elst, L. T. (2018). Education and employment status of adults with autism spectrum disorders in Germany - A crosssectional-survey. BMC Psychiatry, 18(1), 75. https://do i.org/10.1186/s12888-018-1645-7

Gerhardt, P. F., \& Lainer, I. (2011). Addressing the needs of adolescents and adults with autism: A crisis on the horizon. Journal of Contemporary Psychotherapy, 41(1), 37-45. https://doi.org/10.1007/s10879-010-9160-2

Gilbride, D., Stensrud, R., Vandergoot, D., \& Golden, K. (2003). Identification of the characteristics of work environments and employers open to hiring and accommodating people with disabilities. Rehabilitation Counseling Bulletin, 46(3), 130-137. http s://doi.org/10.1177/00343552030460030101 
Gilbride, D., Vandergoot, D., Golden, K., \& Stensrud, R. (2006). Development and validation of the Employer Openness Scale. Rehabilitation Counseling Bulletin, 49(2), 81-89. https://doi.org/10.1177/0034355206049 0020901

Gould, R., Harris, S. P., Mullin, C., \& Jones, R. (2019). Disability, diversity, and corporate social responsibility: Learning from recognized leaders in inclusion. Journal of Vocational Rehabilitation, 52(3), 29-42. https://doi.org/10.3233//VR-191058

Granat, W. L. (2020). First race, then sex, now disability: The fight towards increased and equal employment of individuals with disabilities. Journal of Civil Rights and Economic Development, 2(33), 183-216. https://schola rship.law.stjohns.edu/jcred/vol33/iss2/4/

Grenawalt, T. A., Brinck, E. A., Friefeld Kesselmayer, R., Phillips, B. N., Geslak, D., Strauser, D. R., Chan, F., \& Tansey, T. N. (2020). Autism in the workforce: A case study. Journal of Management \& Organization. Advance online publication. https://doi.org/10.1017/i $\underline{\text { mo.2020.15 }}$

Griffiths, A. J., Hurley-Hanson, A., Giannantonio, C. M., Mathur, S. K., Hyde, K., \& Linstead, E. (2020). Developing employment environments where individuals with ASD thrive: Using machine learning to explore employer policies and practices. Brain Sciences, 10(9), 632-655. https://doi.org/10.3390/brai nsci10090632

Hedley, D., Uljarević, M., Cameron, L., Halder, S., Richdale, A., \& Dissanayake, C. (2017). Employment programmes and interventions targeting adults with autism spectrum disorder: A systematic review of the literature. Autism, 21(8), 929-941. https://doi.org/1 $\underline{0.1177 / 1362361316661855}$

Hendricks, D. (2010). Employment and adults with autism spectrum disorders: Challenges and strategies for success. Journal of Vocational Rehabilitation, 32(2), 125-134. https://doi.org/10.3233/IVR-2010-0502

Howlin, P. (2013). Social disadvantage and exclusion: Adults with autism lag far behind in employment prospects. Journal of the American Academy of Child \& Adolescent Psychiatry, 52(9), 897-899. https://doi.org/ 10.1016/j.jaac.2013.06.010

Huang, I.-C., \& Chen, R. K. (2015). Employing people with disabilities in the Taiwanese workplace: Employers' perceptions and considerations. Rehabilitation Counseling Bulletin, 59(1), 43-54. http s://doi.org/10.1177/0034355214558938

Hurley-Hanson, A. E., Giannantonia, C. M., \& Griffiths, A.-J. (2020). Autism in the workplace: Creating positive employment and career outcomes for Generation A. Palgrave Macmillan.

Hutton, S., Park, P., Park, R., \& Rider, K. (2010). Rights, respect and tokenism: Challenges in self-advocacy. Journal on Developmental Disabilities, 16(1), 109-113.

Johnson, K. R., Ennis-Cole, D., \& Bonhamgregory, M. (2020). Workplace success strategies for employees with autism spectrum disorder: A new frontier for human resource development. Human Resource Development Review. Advance online publication. http s://doi.org/10.1177/1534484320905910
Kendall, K. M., \& Karns, G. L. (2019). The business case for hiring people with disabilities. Social Business, 8(3), 277-292. https://doi.org/10.1362/204440818X15 $\underline{4305418614}$

Krzeminska, A., \& Hawse, S. (2020). Mainstreaming neurodiversity for an inclusive and sustainable future workforce: Autism-spectrum employees. In L. N. Wood, L. P. Tan, Y. Breyer, \& S. Hawes (Eds.), Industry and higher Education: Case studies for sustainable futures (pp. 229-261). Springer.

Kulkarni, M. (2016). Organizational career development initiatives for employees with a disability. The International Journal of Human Resource Management, 27(14), 1662-1679. https://doi.org/10.1080/0958519 $\underline{2.2015 .1137611}$

Lindsay, S., Cagliostro, E., Albarico, M., Mortaji, N., \& Karon, L. (2018). A systematic review of the benefits of hiring people with disabilities. Journal of Occupational Rehabilitation, 28(4), 634-655. https://d oi.org/10.1007/s10926-018-9756-z

Lorenz, T., \& Heinitz, K. (2014). Aspergers - different, not less: Occupational strengths and job interests of individuals with Asperger's syndrome. Plos One, 9(6), e100358. https://doi.org/10.1371/journal.pone.01003 $\underline{58}$

Maraoto, M., \& Pettinicchio, D. (2020, May 21). An equal labor market means that COVID-19 has been especially harmful for vulnerable groups including people with disabilities. USAPP - American Politics and Policy at LSE. https://blogs.lse.ac.uk/usappblog/2 020/05/21/an-unequal-labor-market-means-that-covi d-19-has-been-especially-harmful-for-vulnerable-gr oups-including-people-with-disabilities

Mawhood, L., \& Howlin, P. (1999). The outcome of a supported employment scheme for high-functioning adults with autism or Asperger syndrome. Autism, 3(3), 229-254. https://doi.org/10.1177/136236139900 $\underline{3003003}$

Merriam, S. B., \& Tisdell, E. J. (2016). Designing your study and selecting a sample. In Qualitative research: A guide to design and implementation (4th ed., pp. 73-104). Jossey-Bass.

Miethlich, B., \& Oldenburg, A. G. (2019). The employment of people with disabilities as a strategic asset: A resource-based-view using the value-rarityimitability-organization (VRIO) framework. Journal of Eastern Europe Research in Business and Economics, 2019, 1-13. https://doi.org/10.5171/2019.667087

Miethlich, B., \& Šlahor, L. (2018). Employment of people with disabilities as a corporate social responsibility initiative: Necessity and variants of implementation. CBU International Conference on Innovations in Science and Education, 6, 350-355.

National Organization on Disability. (2020, July 16). New employer survey portends difficult road ahead for people with disabilities who lost their jobs during COVID-19 pandemic. National Organization on Disability. https://www.nod.org/new-employer-surve y-portends-difficult-road-ahead-for-people-with-disa bilities-who-lost-their-jobs-during-covid-19-pandem ic 
Nicholas, D. B., \& Klag, M. (2020). Critical reflections on employment among autistic adults. Autism in Adulthood, 2(4), 289-295. https://doi.org/10.1089/au t.2020.0006

Nicholas, D. B., Mitchell, W., Zulla, R., \& Dudley, C. (2019). Perspectives of employers about hiring individuals with autism spectrum disorder: Evaluating a cohort of employers engaged in a jobreadiness initiative. Journal of Vocational Rehabilitation, 50(3), 353-364. https://doi.org/10.323 3/IVR-191018

Palumbo, J. (2021, April 27). Why Autism Speaks is encouraging companies. Forbes. https://www.forbes.c om/sites/jenniferpalumbo/2021/04/27/why-autism-sp eaks-is-encouraging-companies-to-hire-those-on-th e-autistic-spectrum/?sh=16acc2fd52a2

Procknow, G., \& Rocco, T. S. (2016). The unheard, unseen, and often forgotten: An examination of disability in the human resource development literature. Human Resource Development Review, 15(4), 379-403. https://doi.org/10.1177/1534484316671194

Ross-Gordon, J. M., \& Brooks, A. K. (2004). Diversity in human resource development and continuing professional education: What does it mean for the workforce, clients, and professionals? Advances in Developing Human Resources, 12, 407-428. https://do i.org/10.1177/1523422303260418

Roux, A. M., Shattuck, P. T., Cooper, B. P., Anderson, K. A., Wagner, M., \& Narendorf, S. C. (2013). Postsecondary employment experiences among young adults with an Autism Spectrum Disorder: Employment in young adults with autism. Journal of the American Academy of Child \& Adolescent Psychiatry, 52(9), 931-939. https://doi.org/10.1016/i.j aac.2013.05.019

Roux, A. M., Shattuck, P. T., Rast, J. E., Rava, J. A., \& Anderson, K. A. (2015). National Autism indicators report: Transition into young adulthood. Life Course Outcomes Program, A.J. Drexel Autism Institute, Drexel University.

Shattuck, P. T. (2019, November 13). Drexel prof: Want to be part of a long-overdue adventure? Hire people with intellectual and developmental disabilities. The Philadelphia Inquirer. https://www.inquirer.com/new s/paul-shattuck-drexel-autism-transition-pathwaysdiane-malley-20191113.html
Stone, D. L., \& Colella, A. (1996). A model of factors affecting the treatment of disabled individuals in organizations. Academy of Management Review, 21(2), 352-401. https://doi.org/10.5465/amr.1996.96050602 $\underline{16}$

Theodorakopoulos, N., \& Budhwar, P. (2015). Guest editors' introduction: Diversity and inclusion in different work settings: Emerging patterns, challenges, and research agenda. Human Resource Management, 54(2), 177-197. https://doi.org/10.1002/ hrm.21715

Trullen, J., Stirpe, L., Bonache, J., \& Valverde, M. (2016). The HR department's contribution to line managers' effective implementation of HR practices. Human Resource Management Journal, 26(4), 449-470. http s://doi.org/10.1111/1748-8583.12116

Unger, D. D. (2002). Employers' attitudes toward people with disabilities in the workforce: myths or realities? Focus on Autism and Other Developmental Disabilities, 17(1), 2-10. https://doi.org/10.1177/10883576020170 $\underline{0101}$

Wehman, P. (2003). Workplace inclusion: People with disabilities and coworkers working together. Journal of Vocational Rehabilitation, 18(2), 131-141.

Wehman, P., Schall, C. M., McDonough, J., Graham, C., Brooke, V., Riehle, J. E., Brooke, A., Ham, W., Lau, S., Allen, J., \& Avellone, L. (2017). Effects of an employer-based intervention on employment outcomes for youth with significant support needs due to autism. Autism, 21(3), 276-290. https://doi.or $\mathrm{g} / 10.1177 / 1362361316635826$

Wei, X., Yu, J. W., Wagner, M., Hudson, L., Roux, A. M., Shattuck, P., \& Blackorby, J. (2018). Job searching, job duration, and job loss among young adults with autism spectrum disorder. Journal of Vocational Rehabilitation, 48(1), 1-10. https://doi.org/10.3233/IV $\underline{\mathrm{R}-170922}$

Wharton Business Daily. (2019, March 28). How companies are increasing neurodiversity in the workplace. Knowledge@Wharton. https://knowledg e.wharton.upenn.edu/article/autism-employment

Yin, R. K. (2018). Case study research and applications: Design and methods (6th ed.). Sage. 